\title{
Histamine induces microglia activation and dopaminergic neuronal toxicity via $\mathrm{H} 1$ receptor activation
}

\author{
Sandra M. Rocha ${ }^{1 \dagger}$, Tatiana Saraiva $^{1 \dagger}$, Ana C. Cristóvão ${ }^{1}$, Raquel Ferreira ${ }^{1}$, Tiago Santos ${ }^{1}$, Marta Esteves ${ }^{1}$, \\ Cláudia Saraiva', Goun Je², Luísa Cortes ${ }^{3}$, Jorge Valero ${ }^{3}$, Gillberto Alves ${ }^{1}$, Alexander Klibanov ${ }^{4}$, \\ Yoon-Seong $\mathrm{Kim}^{2}$ and Liliana Bernardino ${ }^{1,5^{*}}$
}

\begin{abstract}
Background: Histamine is an amine widely known as a peripheral inflammatory mediator and as a neurotransmitter in the central nervous system. Recently, it has been suggested that histamine acts as an innate modulator of microglial activity. Herein, we aimed to disclose the role of histamine in microglial phagocytic activity and reactive oxygen species (ROS) production and to explore the consequences of histamine-induced neuroinflammation in dopaminergic (DA) neuronal survival.

Methods: The effect of histamine on phagocytosis was assessed both in vitro by using a murine N9 microglial cell line and primary microglial cell cultures and in vivo. Cells were exposed to lgG-opsonized latex beads or phosphatidylserine (PS) liposomes to evaluate Fcy or PS receptor-mediated microglial phagocytosis, respectively. ROS production and protein levels of NADPH oxidases and Rac1 were assessed as a measure of oxidative stress. DA neuronal survival was evaluated in vivo by counting the number of tyrosine hydroxylase-positive neurons in the substantia nigra (SN) of mice.

Results: We found that histamine triggers microglial phagocytosis via histamine receptor 1 (H1R) activation and ROS production via H1R and H4R activation. By using apocynin, a broad NADPH oxidase (Nox) inhibitor, and Nox1 knockout mice, we found that the Nox1 signaling pathway is involved in both phagocytosis and ROS production induced by histamine in vitro. Interestingly, both apocynin and annexin V (used as inhibitor of PS-induced phagocytosis) fully abolished the DA neurotoxicity induced by the injection of histamine in the SN of adult mice in vivo. Blockade of H1R protected against histamine-induced Nox1 expression and death of DA neurons in vivo.

Conclusions: Overall, our results highlight the relevance of histamine in the modulation of microglial activity that ultimately may interfere with neuronal survival in the context of Parkinson's disease (PD) and, eventually, other neurodegenerative diseases which are accompanied by microglia-induced neuroinflammation. Importantly, our results also open promising new perspectives for the therapeutic use of H1R antagonists to treat or ameliorate neurodegenerative processes.
\end{abstract}

Keywords: Histamine, Microglia, Phagocytosis, NADPH oxidase, Neurotoxicity, Dopaminergic neurons

\footnotetext{
* Correspondence: libernardino@fcsaude.ubi.pt

${ }^{\dagger}$ Equal contributors

'Health Sciences Research Centre, Faculty of Health Sciences, University of Beira Interior, Covilhã, Portugal

${ }^{5}$ Health Sciences Research Centre, University of Beira Interior, Av. Infante D.

Henrique, 6200-506 Covilhã, Portugal

Full list of author information is available at the end of the article
} 


\section{Background}

Histamine is a biogenic amine with extensive effects on several peripheral immune cells and recently highlighted as a promising modulator of brain innate immunity. In the brain, it is produced by histaminergic neurons, mast, and microglial cells [1-6]. Histamine exerts its various functions through the activation of four distinct subtypes of $\mathrm{G}$ protein-coupled receptors (H1R, H2R, H3R, and H4R) [7, 8]. Microglial cells, the innate immune cells in the central nervous system, express all histamine receptors [9], and we were the first to show that histamine modulates N9 microglial cells migration and interleukin$1 \beta$ (IL-1 $\beta$ ) release [7]. Other studies also showed that histamine may also modulate the release of IL-1 $\beta$, tumor necrosis factor (TNF)-alpha, IL-6, nitric oxide (NO), reactive oxygen species (ROS) production and induce mitochondrial membrane potential dysfunction [8-13].

Interestingly, the functional consequences of histamine in microglial phagocytosis remain unexplored. Microglia phagocytose foreign pathogens, stressed/apoptotic cells, and also supernumerary synapses in postnatal development. Several microglia receptors enable the recognition of these targets, namely $F_{c}$-gamma receptors ( $\left.F_{c} \gamma R\right)$, which bind to IgG of opsonized particles, and phosphatidylserine (PS) receptors (PSR), which bind to PS on the outer membrane leaflet of stressed and apoptotic cells. Several other receptors can recognize the exposed PS, such as $\mathrm{T}$ cell/transmembrane, immunoglobulin, and mucin (TIM) -1, TIM-4, and the vitronectin receptor [14-16]. Overall, phagocytosis is considered to be beneficial since it eliminates stressed/apoptotic cells and maintains healthy neuronal networks. However, phagocytosis can also activate the respiratory burst cascade, which produces toxic ROS ultimately inducing cytotoxicity $[16,17]$. In particular, the nicotinamide adenine dinucleotide phosphate (NADPH) oxidase (Nox) system is responsible for producing ROS that are associated with microglial phagocytosis and neuronal death $[18,19]$. Accordingly, herein, we found that histamine induces microglial phagocytosis via H1R activation and ROS production via both $\mathrm{H} 1 \mathrm{R}$ and $\mathrm{H} 4 \mathrm{R}$ activation. Both microglial responses depend on the activation of the Nox system. Therefore, histamine may have an impact on the pathogenesis of brain diseases which are associated with inflammatory conditions. In fact, increased levels of histamine found in the cerebrospinal fluid (CSF) and in brain parenchyma as well as pharmacological experiments and clinical trials suggest that the histaminergic system may be implicated in the etiology and/or progression of several neurodegenerative diseases [20, 21] such as Parkinson's disease (PD) [22-25]. In fact, it has been shown that the substantia nigra $(\mathrm{SN})$ is a brain region highly vulnerable to the neurotoxic actions of microglia [14, 26] and in particular to histamine [27].
Recently, we also showed that the secretome of microglial cells exposed to histamine induces degeneration of dopaminergic (DA) neurons in vitro [8]. However, the cellular and molecular mechanisms behind these toxic effects are not known. Importantly, our present results also highlight the potential of H1R antagonists to prevent DA cell loss derived from histamine-induced microglial neuroinflammation in vivo. Altogether, we present novel findings that unravel the effects of histamine in microglial-induced DA neuronal death and the potential therapeutic application of H1R antagonist to counteract these toxic effects.

\section{Methods}

\section{N9 microglial cell line cultures}

Murine N9 microglia cell line was grown in modified Roswell Park Memorial Institute (RPMI) medium (SigmaAldrich, St. Louis, MO, USA) during 24 h at $37{ }^{\circ} \mathrm{C}$ in $5 \%$ $\mathrm{CO}_{2}$ and $95 \%$ atmospheric air, as previously described by us [28]. Cells were plated at a density of $2 \times 10^{4}$ cells per well in 24-well trays (phagocytic studies and immunocytochemistry), $5 \times 10^{5}$ cells per well in 6-well trays (protein extraction), or $5 \times 10^{4}$ cells per well in 96-well trays (ROS measurements). Cell treatments included the following incubation setup: histamine dihydrochloride (1, 10, and $100 \mu \mathrm{M}$, Sigma-Aldrich), H1R antagonist (mepyramine maleate, $1 \mu \mathrm{M}$ ), H2R antagonist (cimetidine, $5 \mu \mathrm{M}$ ), H3R antagonist (carcinine ditrifluoroacetate, $5 \mu \mathrm{M}), \mathrm{H} 4 \mathrm{R}$ antagonist (JNJ7777120, $5 \mu \mathrm{M}$ ), H1R agonist (2-pyridylethylamine dihydrochloride, $100 \mu \mathrm{M}), \mathrm{H} 4 \mathrm{R}$ agonist (4methylhistamine dihydrochloride, $20 \mu \mathrm{M}$ ) (all from Tocris Bioscience, Bristol, UK), and apocynin (5 $\mu \mathrm{M}$, SigmaAldrich). All histamine receptor antagonists and apocynin were added $1 \mathrm{~h}$ prior to cell treatments and maintained during the course of the experiments.

\section{Primary murine microglia cell cultures}

Postnatal whole brain microglia cultures of wild-type (WT) and Nox1 knockout (Nox1-KO) mice were prepared as previously reported [29]. Briefly, the whole brain of 3-5-day postnatal mice pups were dissected, carefully stripped of meninges, and mechanically dissociated with a 5-ml pipette, followed by 5-10 sequential passages through 20-, 22-, and 25-gauge needles. Finally, cells were passed through a $70 \mu \mathrm{m}$ mesh, pelleted by centrifugation, suspended in high-glucose Dulbecco's modified Eagle medium (DMEM) with 10 \% fetal bovine serum (FBS) and 100 units $/ \mathrm{ml}$ penicillin plus $100 \mu \mathrm{g} / \mathrm{ml}$ streptomycin (all from Sigma-Aldrich), and plated onto $25 \mathrm{~cm}^{2}$ poly-D-lysine-coated culture flasks (one brain per flask). The cultures were kept at $37{ }^{\circ} \mathrm{C}$ in a $5 \% \mathrm{CO}_{2}$, $95 \%$ air atmosphere. The medium was changed every 4 days. On day 14, the culture flasks were shaken during $2 \mathrm{~h}$ at $200 \mathrm{rpm}$ to detach microglial cells, leaving 
astrocytes in an adherent monolayer. The microgliaenriched supernatant was collected and centrifuged for $10 \mathrm{~min}$ at $1200 \mathrm{rpm}$. The pellet was then suspended in DMEM, and the microglial cells were plated onto polyD-lysine-coated coverslips and kept at $37{ }^{\circ} \mathrm{C}$ in a $5 \%$ CO2, $95 \%$ air atmosphere until used. The culture medium was replaced every 4 days. Each pup was genotyped to confirm its phenotype as WT or Nox1-KO.

\section{In vitro phagocytosis assays \\ FcyR-mediated phagocytosis}

Latex beads (Sigma-Aldrich) were opsonized with rabbit IgG $(1 \mu \mathrm{g} / \mathrm{ml}$, Sigma-Aldrich) under constant agitation overnight at $4{ }^{\circ} \mathrm{C}$. Then, the beads were resuspended in modified RPMI medium without $\mathrm{NaHCO}_{3}$ (SigmaAldrich) and distributed at a density of $1 \times 10^{5}$ beads per well, over cells that were previously exposed to histamine for $6 \mathrm{~h}$. After $40 \mathrm{~min}$ of incubation with the beads, the cells were washed with phosphate-buffered saline (PBS) and fixed with $4 \%$ paraformaldehyde (PFA, SigmaAldrich) for $20 \mathrm{~min}$ at room temperature (RT). Extracellular and/or adherent beads were labeled with secondary antibody Alexa Fluor 594 donkey anti-rabbit (1:500, Life Technologies Ltd, Paisley, UK) in PBS, for $1 \mathrm{~h}$ at RT. For nuclear labeling, cell preparations were stained with Hoechst 33342 (2 $\mu \mathrm{g} / \mathrm{ml}$, Life Technologies Ltd.) in PBS, for $5 \mathrm{~min}$ at RT. Coverslips were then mounted in Dako fluorescent medium (Dakocytomation Inc., Glostrup, Denmark). Confocal images were acquired using an Axio Observer LSM710 confocal microscope (Zeiss) under a $63 \times$ oil objective. For each coverslip, five photomicrographs were acquired in order to capture stained nuclei (in blue), extracellular and/or adherent beads (in red), and the total number of beads (differential interference contrast image). The location of each bead was analyzed by comparing the three separate images simultaneously. Only beads without fluorescent labeling were considered as internalized particles.

\section{PS-mediated phagocytosis}

Fluorescent-labeled PS or phosphatidylcholine (PC)-containing liposomes $(5 \mu \mathrm{l} /$ well $)$ were added to the cells previously exposed to histamine for $6 \mathrm{~h}$. PC liposomes were used as a negative control for PS-dependent phagocytosis. To block PS-induced phagocytosis, annexin V (4 $\mu \mathrm{l} /$ well), which binds to PS residues, was added $1 \mathrm{~h}$ prior to incubation with liposomes. After $2 \mathrm{~h}$ of exposure to liposomes, the cells were washed with RPMI medium and then fixed with $4 \%$ PFA. After several rinses with PBS, unspecific binding was prevented by incubating cells in a $3 \%$ BSA and $0.5 \%$ Triton X-100 solution (all from Sigma-Aldrich) in PBS, for $30 \mathrm{~min}$ at RT. Then, the cells were incubated overnight at $4{ }^{\circ} \mathrm{C}$ with primary antibody rat monoclonal anti-CD $11 b$
(1:600; AbD Serotec, Oxford, UK) diluted in PBS containing $0.3 \%$ BSA and $0.1 \%$ Triton X-100. After several washes with PBS, the cells were incubated for $1 \mathrm{~h}$ at RT with the corresponding secondary antibody Alexa Fluor 488 goat anti-rat (1:200; Life Technologies Ltd) diluted in PBS. For nuclear labeling, cell preparations were stained with Hoechst $33342(2 \mu \mathrm{g} / \mathrm{ml}$; Life Technologies Ltd) in PBS, for $5 \mathrm{~min}$ at RT and mounted in a Dako fluorescent medium. Fluorescent images were acquired using an Axio Observer LSM710 confocal microscope (Zeiss) under a $40 \times$ oil objective. Photomicrographs were acquired using the same acquisition settings in each experimental protocol. For each experimental setting, we first outlined microglial cytoplasm by staining CD11b (in green) and the corrected fluorescence intensity of PS/PC liposomes (in red) was subtracted from the fluorescence background. Similar protocols reported by others were used to quantify microglial phagocytosis of synaptic inputs (presynaptic terminals), axonal or myelin debris, and neurofilament-positive axonal material [30-32]. Quantification of fluorescence intensity of the PS/PC liposomes was performed with at least 64 cells per condition. Analysis was performed using the ImageJ software.

\section{Liposome preparation}

Liposomes (diameter 2-6 $\mu \mathrm{m}$ ) were prepared by a classical Bangham technique. Multilamellar vesicles were chosen to maximize the fluorescent-dye load per particle without significant self-quenching [33]. Briefly, dioleoyl phosphatidylcholine (Avanti Polar Lipids, Alabama, USA) and cholesterol (Sigma-Aldrich) were mixed in chloroform at 1:1 molar ratio, and DiIC18(3) dye (Life Technologies Ltd.) was added; this dye has two stearyl residues attached to the fluorochrome, so it is tightly attached to the liposome membrane and is not exchangeable. PS (Avanti Polar Lipids) was added at 1:10 PS to PC mass ratio to the experimental sample but not to control. After chloroform removal by rotary evaporation and argon gas flush, vacuum desiccation was applied to remove traces of organic solvent. After the complete removal of the solvent, normal saline was added to the lipid film and the sample was subjected to hydration under vortexing.

\section{Measurements of cellular ROS levels}

ROS levels were measured using a dihydroethidium probe (DHE, Life Technologies Ltd), as described previously by us [34]. In the DHE assay, blue fluorescent DHE is dehydrogenated by superoxide $\left(\mathrm{O}_{2}^{-}\right)$to form red fluorescent ethidium bromide. The cells exposed for $2 \mathrm{~h}$ to stimuli were then incubated for $4 \mathrm{~h}$ (N9 cell line) or $20 \mathrm{~min}$ (primary murine microglial cells) with $100 \mu \mathrm{M}$ DHE in culture medium at $37{ }^{\circ} \mathrm{C}$. The emitted fluorescence (excitation $515 \mathrm{~nm}$; emission $605 \mathrm{~nm}$ ) was 
read in a spectrofluorometer (SpetroMax GeminiEM; Molecular Devices).

\section{Immunocytochemistry}

The cells were fixed with $4 \%$ PFA, and unspecific binding was prevented by incubating cells in a $3 \%$ BSA and $0.5 \%$ Triton X-100 solution (all from Sigma-Aldrich) for $30 \mathrm{~min}$ at RT. The cells were incubated with primary antibodies prepared in $0.3 \%$ BSA and $0.1 \%$ Triton X-100, kept overnight at $4{ }^{\circ} \mathrm{C}$, washed with $\mathrm{PBS}$, and finally incubated for $1 \mathrm{~h}$ at RT with the corresponding secondary antibody. Antibodies used were as follows: rat monoclonal anti-CD11b (1:600; AbD Serotec), mouse monoclonal anti-acetylated $\alpha$-tubulin (1:100; Sigma-Aldrich), goat polyclonal anti-Nox1 (1:250; Santa Cruz Biotechnology, Heidelberg, Germany), Alexa Fluor 594 goat anti-rat, Alexa Fluor 488 goat anti-rat, Alexa Fluor 488 donkey anti-goat, and Alexa Fluor 594 rabbit anti-mouse (all 1:200 in PBS, from Life Technologies Ltd). Membrane ruffling was observed using phalloidin, a marker for filamentous actin. The cells were incubated for $2 \mathrm{~h}$ with Alexa Fluor 594 conjugated to phalloidin (1:100; Life Technologies Ltd) in PBS, at RT. For nuclear labeling, cell preparations were stained with Hoechst $33342(2 \mu \mathrm{g} / \mathrm{ml}$, Life Technologies Ltd) in PBS, for $5 \mathrm{~min}$ at RT and mounted in Dako fluorescent medium. Fluorescent images were acquired using an Axio Observer LSM710 confocal microscope (Zeiss) under a $63 \times$ oil objective.

\section{Western blotting}

The cells were washed with ice-cold PBS and lysed on ice in RIPA buffer (50 mM Tris- $\mathrm{HCl}, \mathrm{pH} 8.0,150 \mathrm{mM}$ $\mathrm{NaCl}, 2 \mathrm{mM}$ sodium orthovanadate, $1 \%$ Nonidet-P40, $0.5 \%$ sodium deoxycholate, $0.1 \%$ SDS, and $1 \%$ of a protease inhibitor mixture containing 4-(2-aminoethyl)benzenesulfonyl fluoride hydrochloride, pepstatin A, E-64, bestatin, leupeptin, and aprotinin, all from SigmaAldrich). After gentle homogenization, the total amount of protein was quantified using the Bradford method (Bio-Rad Protein Assay, Bio-Rad, Hertz, UK). Afterwards, the samples were loaded onto $12 \%$ acrylamide/ bisacrilamide gels (Bio-Rad). Proteins were separated by SDS-PAGE and then transferred to PVDF membranes (Amersham Hybond ${ }^{\mathrm{TM}}$-P, GE Healthcare, Little Chalfont, UK). The membranes were then blocked with $5 \%$ non-fat milk in Tris-buffered saline with $0.1 \%$ Tween 20 (TBS-T) for $1 \mathrm{~h}$ at RT. Incubation with mouse monoclonal anti-acetylated $\alpha$-tubulin (1:200; Sigma-Aldrich), goat polyclonal anti-Nox1 (1:200; Santa Cruz Biotechnology), goat polyclonal anti-Nox2 (1:2000; BD Laboratories, San Jose, CA, USA), goat polyclonal anti-Nox4 (1:200; Santa Cruz Biotechnology), and mouse monoclonal anti-Rac1 (1:750; Millipore, Billerica, MA, USA) diluted in TBS-T was done overnight at $4{ }^{\circ} \mathrm{C}$. After rinsing three times with TBS-T, the membranes were incubated for $1 \mathrm{~h}$ at RT with an anti-mouse (1:10,000; GE Healthcare) or anti-goat antibody (1:10,000; Santa Cruz Biotechnology) diluted in TBS-T. The membranes were then incubated with ECF substrate (ECF Western Blotting Reagent Packs, GE Healthcare) for $5 \mathrm{~min}$. Protein bands were detected using the Molecular Imager FX system (Bio-Rad) and quantified by densitometry analysis using the Quantity One software (Bio-Rad).

\section{In vivo experiments}

Wild-type C57BL/6 male mice (8 to 12 weeks) were maintained in appropriate cages, under temperature-controlled environment under a $12 \mathrm{~h}$ light/dark cycle with free access to food and water. All experiments related to the use of experimental animal models were conducted in compliance with protocols approved by the national ethical requirements for animal research, the European Convention for the Protection of Vertebrate Animals Used for Experimental and Other Scientific Purposes (European Union Directive number 2010/63/EU). Before stereotaxic surgery, the mice were anesthetized with an intraperitoneal injection (i.p.) of ketamine and xylazine $(90 \mathrm{mg} / \mathrm{kg}$ and $10 \mathrm{mg} / \mathrm{kg}$, respectively).

To analyze DA neuronal survival, the mice were unilaterally injected with $2 \mu \mathrm{l}$ of sterile PBS or histamine (100 $\mu \mathrm{M}$ in PBS) in the right lateral SN (coordinates related to the bregma: $\mathrm{AP}=+3.0 \mathrm{~mm} ; \mathrm{ML}=-1.4 \mathrm{~mm}$; $\mathrm{DV}$ $=-4.4 \mathrm{~mm}$; according to [35]) using a stereotaxic frame (Stoelting 51600, IL, USA). In another set of animals, $2 \mu \mathrm{l}$ of sterile H1R antagonist (mepyramine maleate, $1 \mu \mathrm{M}$ ) or H4R antagonist (JNJ7777120, $5 \mu \mathrm{M}$ ) were also injected following histamine administration. Stereotaxic injections were made using a $10 \mu \mathrm{l}$ Hamilton syringe (Hamilton Company) at a rate of $0.2 \mu \mathrm{l} / \mathrm{min}$ during $10 \mathrm{~min}$. The needle was removed and the incision sutured. Apocynin (4 mg/kg, i.p.) or annexin V (5 $\mu \mathrm{g} /$ mouse, intravenously (i.v.)) were administrated $30 \mathrm{~min}$ before and also $24 \mathrm{~h}$ after stereotaxic injections, as described previously by others $[33,36]$. Seven-day (for DA neuronal survival analysis) or 3-day (for co-localization between $\mathrm{CD} 11 \mathrm{~b}+/ \mathrm{TH}+/$ annexin V, Nox1+/CD11b+ or Nox $1+/ \mathrm{TH}+$ ) upon all injections, the mice were transcardially perfused with $0.9 \% \mathrm{NaCl}$ and fixed with $4 \%$ PFA. The brains were removed and post-fixed in $4 \%$ PFA overnight at $4{ }^{\circ} \mathrm{C}$. After fixation, the brains were cryoprotected in $30 \%$ sucrose (in $0.1 \mathrm{M}$ PBS) at $4{ }^{\circ} \mathrm{C}$ until sinking, frozen in liquid nitrogen, and maintained at $-80{ }^{\circ} \mathrm{C}$. Before sectioning, the brains were embedded in an optimal cutting temperature medium (OCT) and cut into $35-\mu \mathrm{m}$ coronal sections using a cryostatmicrotome (Leica CM3050S, Leica Microsystems) at $-20{ }^{\circ} \mathrm{C}$. Slices corresponding to the $\mathrm{SN}$ of each animal 
were collected for immunohistochemical processing, as described previously by us [37].

For the in vivo phagocytosis assays, the mice were stereotaxically injected into the right SN with $1 \mu \mathrm{l}$ of PS liposomes followed by histamine treatment (as described above). Perfusion was performed $18 \mathrm{~h}$ after the stereotaxic injections. The brains were removed, fixed in $4 \%$ PFA, and cut as stated previously. Floating sections $(35 \mu \mathrm{m})$ were then analyzed for phagocytic cells (CD11b + cells with liposome detection).

\section{Fluorescent immunohistochemistry staining}

SN slices were permeabilized with $1 \%$ Triton X-100 in $0.1 \mathrm{M}$ PBS, for $45 \mathrm{~min}$ at RT. Non-specific binding sites were blocked with $10 \% \mathrm{FBS}$ in PBS for $30 \mathrm{~min}$ at RT. In a group of slices, permeabilization was performed only after incubation with Alexa Fluor 488 annexin V conjugate. Then, the slices were incubated with the primary antibodies: rat monoclonal anti-CD11b (1:600; AbD Serotec), goat polyclonal anti-Nox1 (1:200; Santa Cruz Biotechnology), and mouse monoclonal anti-TH antibody (1:1000; BD Laboratories), diluted in $10 \%$ FBS in PBS, overnight at $4{ }^{\circ} \mathrm{C}$. After several washes with $0.1 \%$ Triton X-100 (PBS-T), the slices were incubated with the respective secondary antibodies, Alexa Fluor 594 or 488 goat anti-rat, Alexa Fluor 647 anti-mouse, or Alexa Fluor 546 anti-goat (all 1:200; Life Technologies Ltd) diluted in PBS, for $2 \mathrm{~h}$ at RT. Following nuclei counterstaining with Hoechst $33342(2 \mu \mathrm{g} / \mathrm{ml}$; Life Technologies Ltd) in PBS for 5 min at RT, the sections were mounted in glass slides with a Dako mounting medium. Fluorescent images were acquired using an Axio Observer LSM710 confocal microscope (Zeiss) under a $63 \times$ oil objective. To quantify microglial phagocytosis of liposomes, three distinct brain slices containing the SN [37] were selected per mouse, and in each slice, three pictures were taken within a range of approximately $200 \mu \mathrm{m}$ from the liposomes injection site. The volume of CD11b-positive cells containing PS liposomes was then quantified by orthogonal analysis as described previously [33].

\section{Immunohistochemistry for Tyrosine Hydroxylase (TH)}

Free-floating immunohistochemistry was initiated by incubating SN sections in a $10 \mathrm{mM}$ citrate solution $(\mathrm{pH}$ 6.0) at $80{ }^{\circ} \mathrm{C}$ [37]. After cooled to RT, the slices were placed in water for $5 \mathrm{~min}$ and then washed in PBS-T. The sections were blocked with $10 \%$ FBS in PBS for $1 \mathrm{~h}$ at RT and washed twice with PBS-T. For the inhibition of endogenous peroxidase activity, the brain sections were incubated for $10 \mathrm{~min}$ in $3 \% \mathrm{H}_{2} \mathrm{O}_{2}$. This step was followed by two washes with PBS-T. Incubation with mouse monoclonal anti-TH antibody (1:1000; BD Laboratories) diluted in $5 \%$ FBS in PBS was performed overnight at $4{ }^{\circ} \mathrm{C}$. After washing with PBS-T, the slices were incubated for $1 \mathrm{~h}$ at $\mathrm{RT}$ with a biotinylated goat anti-mouse antibody (1:200; Vector Laboratories, Peterborough, UK) diluted in $1 \%$ FBS. The sections were washed again and incubated with the avidin-biotin peroxidase complex reagent ( $\mathrm{ABC}$ kit from Vector Laboratories) for $30 \mathrm{~min}$ at RT. Then, the sections were developed using 3,3' -diaminobenzidine (Sigma-Aldrich) in TBS with $30 \% \mathrm{H}_{2} \mathrm{O}_{2}$, mounted onto Superfrost precleaned coated slides, dehydrated through a graded ethanol series, cleared using xylene and coversliped with Entellan mounting medium (Merck, Kenilworth, NJ, USA). Quantitative analysis of DA neurons in $\mathrm{SN}$ was carried out by serial section analysis of the total number of TH-positive neurons throughout the rostro-caudal axis. The region corresponding to the $\mathrm{SN}$ was carefully delineated and the total number of TH-positive neurons in the full extent of this structure was counted per section in each hemisphere, as described previously by us [37].

\section{Data analysis}

Data are expressed as percentage of values obtained in control conditions or as percentage of the total number of cells and are presented as mean \pm SEM of at least three independent experiments. Statistical analysis was performed using paired or unpaired $t$ test (whenever appropriate) or one-way ANOVA followed by Bonferroni's multiple comparison test, as indicated in the figure legends. Values of $P<0.05$ were considered significant. All statistical procedures were performed using GraphPad Prism 5 (GraphPad Software Inc.).

\section{Results}

Histamine promotes microglial phagocytosis

We first evaluated the effect of histamine on $\mathrm{Fc} \gamma \mathrm{R}$ mediated phagocytosis in murine N9 microglial cell line. Microglial cells were allowed to internalize IgG-opsonized latex beads for $40 \mathrm{~min}$ followed by an incubation with a secondary antibody Alexa Fluor 594 to distinguish extracellular and/or adherent beads (red labeling) from internalized beads (no fluorescent labeling) (Fig. 1a). Phagocytosis was addressed by counting the total number of internalized beads per cell. We showed that IgG bead phagocytosis increased with escalating concentrations of histamine, reaching about a 2.5-fold increase when $100 \mu \mathrm{M}$ histamine was added to cells $(P<0.001$, Fig. 1a, b). At this concentration, histamine did not interfere with cell death or proliferation (data not shown). Based on these results and on prior studies reported by us $[8,38,39]$, we then used $100 \mu \mathrm{M}$ histamine in further experiments, a concentration of pathophysiological relevance. In order to identify which histamine receptor was involved in phagocytosis, we treated microglial cells with the antagonists for each receptor before histamine treatment. Our results showed that only H1R 
a
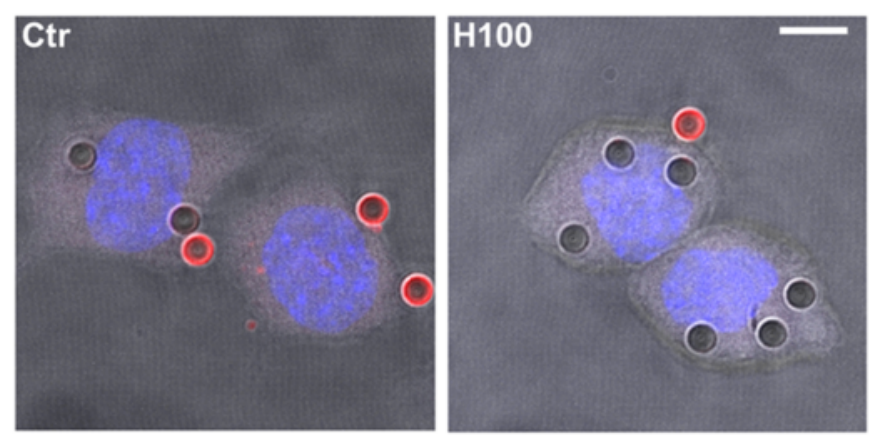

b

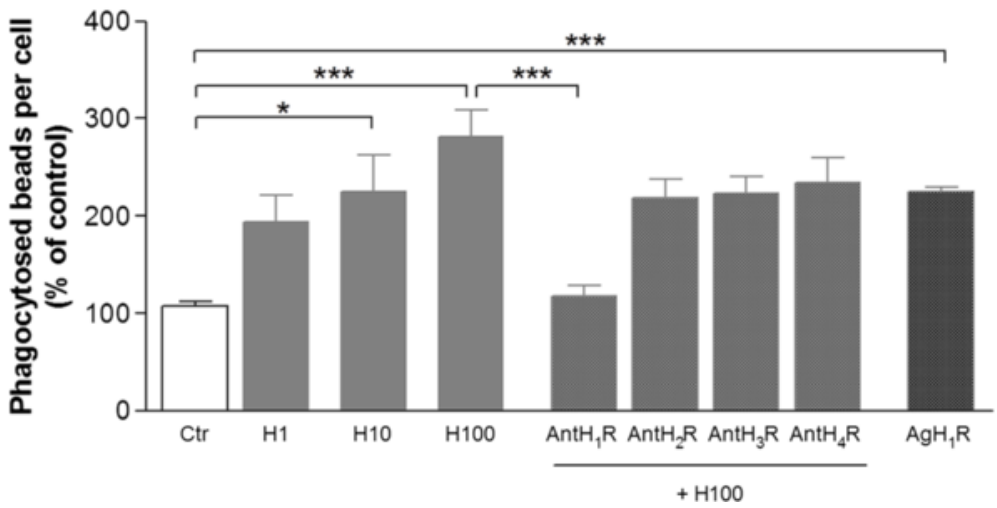

Fig. 1 Histamine-induced microglial FcyR-mediated phagocytosis through H1R activation. a Representative photomicrographs illustrate the stimulatory effect of $100 \mu \mathrm{M}$ histamine on microglial phagocytosis of IgG latex beads. Non-ingested beads display red labeling whereas ingested beads do not show any fluorescence signal. Scale bar $10 \mu \mathrm{m}$. b Only 10 (H10) and 100 (H100) $\mu \mathrm{M}$ histamine significantly increased the number of phagocytosed IgG latex beads per cell as compared with untreated controls (Ctr). Microglial phagocytosis induced by $100 \mu \mathrm{M}$ histamine was fully blocked by an H1R antagonist (AntH1R, mepyramine maleate, $1 \mu \mathrm{M}$ ) and mimicked by an $\mathrm{H} 1 \mathrm{R}$ agonist (AgH1R, 4-methylhistamine dihydrochloride, $20 \mu \mathrm{M}$ ). The involvement of other receptors was excluded since the application of their respective antagonists ("Ant") did not interfere with the phagocytosis-inducing effect of histamine ( $\mathrm{H} 2 \mathrm{R}$ antagonist (cimetidine), $5 \mu \mathrm{M} ; \mathrm{H} 3 \mathrm{R}$ antagonist (carcinine ditrifluoroacetate), $5 \mu \mathrm{M}$; and H4R antagonist (JNJ7777120), $5 \mu \mathrm{M})$. Data are expressed as mean \pm SEM $(n=5-15)$. ${ }^{*} P<0.05$ and ${ }^{* * *} P<0.001$, using one-way ANOVA followed by Bonferroni's multiple comparison test

antagonist (mepyramine maleate, $1 \mu \mathrm{M}$ ) significantly abolished histamine-induced phagocytosis when compared with histamine per se $(P<0.001$, Fig. $1 \mathrm{~b})$. Consistently, an H1R agonist (2-pyridylethylamine, $100 \mu \mathrm{M}$ ) was able to mimic the effect induced by histamine (Fig. 1b). Antagonists for H2R (cimetidine, $5 \mu \mathrm{M}$ ), H3R (carcinine ditrifluoroacetate, $5 \mu \mathrm{M}$ ) or H4R (JNJ7777120, $5 \mu \mathrm{M})$ were not efficient in abolishing histamine-induced phagocytosis (Fig. 1b). These data suggest that histamineinduced Fc $\gamma \mathrm{R}$-microglial phagocytosis of opsonized beads via $\mathrm{H} 1 \mathrm{R}$ activation.

Then, we determined whether histamine could also modulate PSR-mediated phagocytosis using fluorescent PS or PC liposomes, as described in [33]. For this purpose, N9 microglial cells were exposed to $100 \mu \mathrm{M}$ histamine for $6 \mathrm{~h}$ followed by $2 \mathrm{~h}$ incubation with PS or PC liposomes (Fig. 2a). We found that histamine significantly increased by twofold the phagocytosis/uptake of PS liposomes $(P<0.05$; Fig. 2a). Annexin V which binds to PS residues was used as an inhibitor of PS-induced phagocytosis. As expected, annexin V fully abolished the histamine-induced uptake of PS liposomes (Fig. 2a). No significant differences were found in the levels of PC liposomes phagocytosis when cells were treated with histamine as compared to the controls (histamine: 139.7 \pm 29.2 as compared with the control - set to $100 \%, n=$ 3-4). Then, we evaluated the effect of histamine in microglia phagocytosis in vivo by injecting histamine in the SN of mice followed by PS liposomes. The volume of CD11b-positive (+) cells (resident microglial cells/invading macrophages) containing PS liposomes was quantified as described previously by others [33]. As expected, histamine significantly increased the percentage of volume of CD11b+ cells containing PS liposomes as compared with saline mice $(P<0.05$; Fig. $2 b)$. The physiological relevance of the aforementioned results was then validated by investigating the ability of microglial cells to phagocyte PS residues on the membrane of stressed/dying neurons upon histamine exposure in vivo. The stereotaxic injection of histamine in the $\mathrm{SN}$ for 

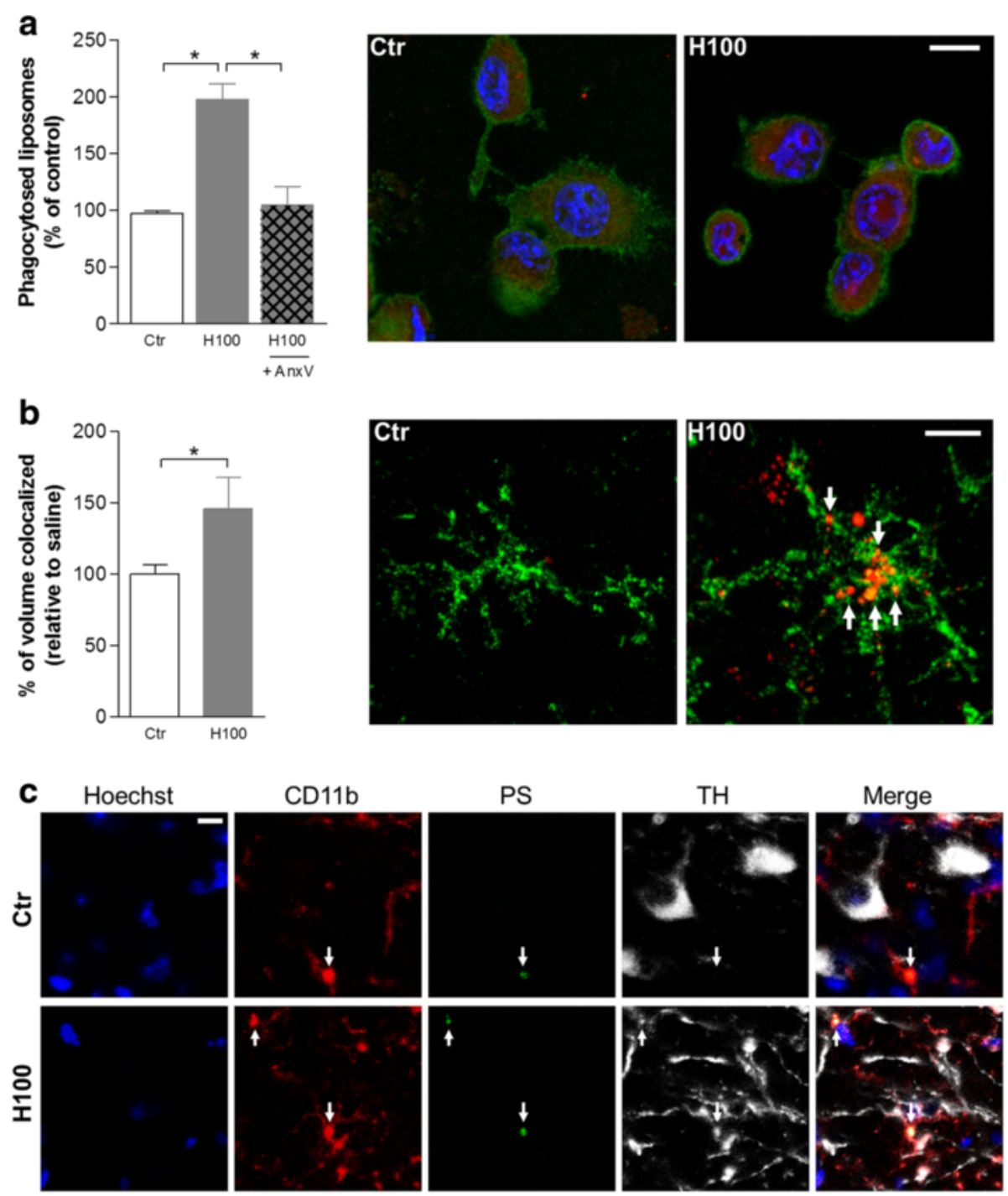

Fig. 2 Histamine-induced microglial phagocytosis of PS particles/residues. a Bar graph displays the stimulatory effect of $100 \mu M$ histamine (H100) on the phagocytosis of phosphatidylserine (PS)-conjugated liposomes in vitro. Specific effect on PS-induced phagocytosis was ruled out by using annexin $\checkmark\left(\right.$ AnxV). Data are expressed as mean \pm SEM $(n=2-10)$ and as a percentage of control. ${ }^{*} P<0.05$, using one-way ANOVA followed by Bonferroni's multiple comparison test. Right panel: representative photomicrographs illustrate the stimulatory effect of $100 \mu \mathrm{M}$ histamine on microglial phagocytosis of PS liposomes in vitro. PS liposomes: red labeling; CD11b: green labeling; nuclei (Hoechst 33342): blue. Scale bar $10 \mu \mathrm{m}$. b The bar graph represents the volume of CD11b+ cells containing PS liposomes in SN slices from mice injected intracranially with $100 \mu \mathrm{M}$ histamine for $18 \mathrm{~h}$. Data are expressed as mean \pm SEM $\left(n=4-6\right.$ mice) and as a percentage of saline. ${ }^{*} P<0.05$, using an unpaired $t$ test as compared with saline mice. Right panel: representative photomicrographs illustrate the stimulatory effect of histamine on microglial phagocytosis of PS liposomes in vivo. PS liposomes: red labeling; CD11b: green labeling; nuclei (Hoechst 33342): blue. Arrows highlight co-labeling events. Scale bar $10 \mu \mathrm{m}$.

c Representative confocal photomicrographs showing that the stereotaxic injection with $100 \mu \mathrm{M}$ histamine (H100) in the SN of adult mice for 3 days induced co-localization (highlighted with white arrows) between PS residues (green), CD11b labeling (red), and TH dopaminergic neuronal staining (white). This co-localization was less evident in saline animals. Cell nuclei were stained with Hoechst 33342 (in blue). Scale bar $10 \mu \mathrm{m}$

3 days triggered a relative higher number of colocalization events between $\mathrm{CD} 11 \mathrm{~b}+, \mathrm{TH}+$, and annexin $\mathrm{V}+$. These co-localization events were less evident in saline animals (Fig. 2c). Altogether, these results suggest that histamine induces phagocytosis of particles and cells displaying PS residues on their surfaces both in vivo and in vitro, likely increasing the vulnerability of stress/dying neurons to microglia phagocytosis.
Histamine triggers microglial cytoskeleton modifications

To further explore the cytoskeleton modifications behind histamine-mediated phagocytosis, microglial cells were stimulated with $100 \mu \mathrm{M}$ histamine for $1 \mathrm{~h}$ for actin filaments (phalloidin staining), and for 12 or $24 \mathrm{~h}$ for microtubule stabilization evaluation (acetylated $\alpha$-tubulin protein levels). Histamine-induced membrane ruffling by actin polymerization and 

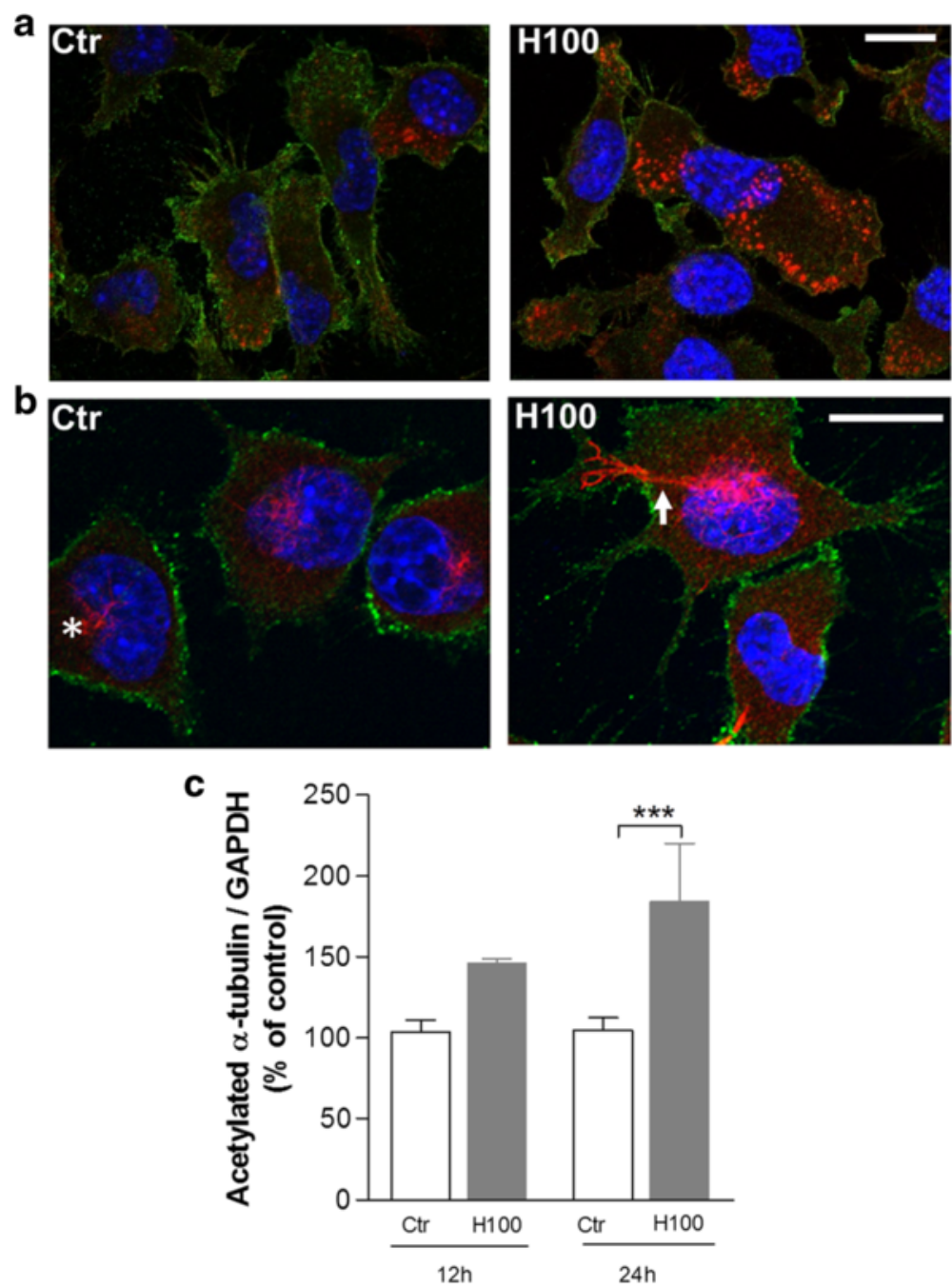

Fig. 3 Histamine-induced microglial cytoskeleton rearrangement. a Representative confocal photomicrographs showing that $100 \mu \mathrm{M}$ histamine (H100) induced membrane ruffling. Cells were stained for phalloidin (red), CD11b (green), and Hoechst 33342 (nuclei in blue). b Histamine also increased a-tubulin acetylation expression levels especially in some microglial processes (white arrows) as compared with the faint staining present in microtubule organization centers (asterisk) found in resting microglial cells, as detected by immunolabeling for acetylated a-tubulin (red), CD1 1b (green), and Hoechst 33342 (nuclei in blue). Scale bars $10 \mu \mathrm{m}$. c Bar graph displays the increased expression levels of acetylated a-tubulin in histamine-activated cells. Data are expressed as mean \pm SEM $(n=4-8)$ and as a percentage of control. ${ }^{* * *} P<0.001$, using one-way ANOVA followed by Bonferroni's multiple comparison test

punctuate staining in structures involved in the initiation of phagocytosis (Fig. 3a). In addition, we found that in unstimulated microglial cells (control) acetylated $\alpha$-tubulin staining was found predominantly confined to the centrosome tubules (Fig. 3b). In contrast, histamine induced an increase of acetylated $\alpha$-tubulin labeling particularly in several microglial processes that may be involved in the stabilization of phagocytic cups/protrusions (Fig. 3b). In accordance, acetylated $\alpha$-tubulin protein expression levels were significantly increased by histamine $(1.8$-fold increase, $P<0.001)$ at $24 \mathrm{~h}$ post-treatment as compared with the controls
(Fig. 3c). These results suggest that histamine induces cytoskeleton alterations associated with microglia phagocytosis dynamics.

Oxidative stress contribution to histamine-induced microglial phagocytosis

Then, we evaluated the effect of histamine on ROS production and the putative contribution of ROS for microglial phagocytosis. As shown in Fig. 4a (N9 cell line) and in Additional file 1: Figure S1 (primary murine microglia cells), $100 \mu \mathrm{M}$ histamine significantly increased ROS levels when compared to control $(P<0.001)$. ROS 

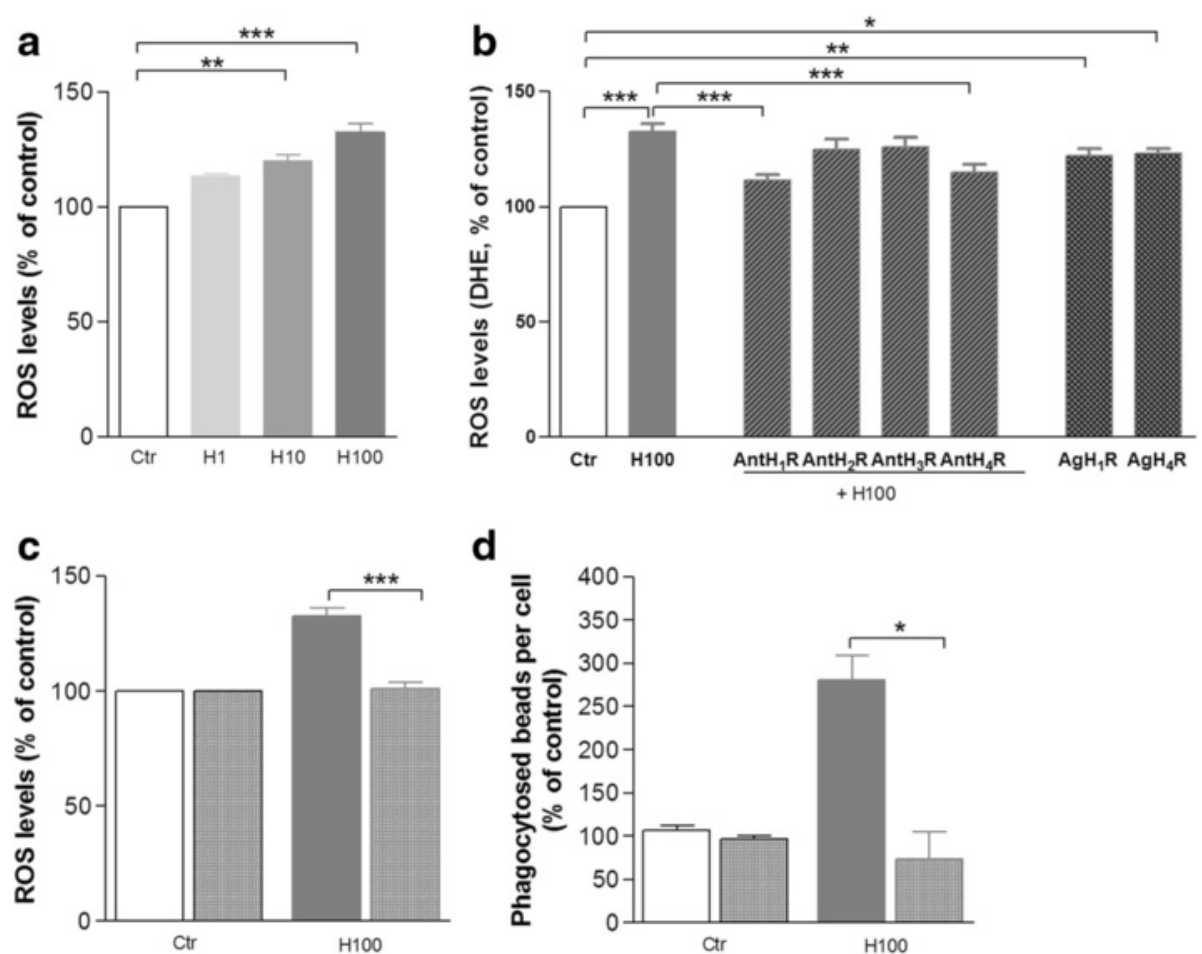

Fig. 4 Histamine-induced ROS generation contributes to microglial phagocytosis. a Only 10 (H10) and $100 \mu \mathrm{M}$ histamine (H100) significantly increased the levels of ROS as compared with untreated controls (Ctr). b Cellular ROS production induced by $100 \mu \mathrm{M}$ histamine was blocked by an H1R antagonist (AntH1R, mepyramine maleate, $1 \mu \mathrm{M}$ ) or H4R antagonist (AntH4R, JNJ7777120, $5 \mu \mathrm{M}$ ) and mimicked by an H1R agonist ( $\mathrm{AgH1}$ R, 4-methylhistamine dihydrochloride, $20 \mu \mathrm{M}$ ) or a H4R agonist (4-methylhistamine dihydrochloride, $20 \mu \mathrm{M}$ ). The involvement of other receptors was excluded since the application of their respective antagonists did not interfere with ROS levels induced by histamine (H2R antagonist (cimetidine), $5 \mu \mathrm{M} ; \mathrm{H} 3 \mathrm{R}$ antagonist (carcinine ditrifluoroacetate), $5 \mu \mathrm{M})$. Apocynin $(5 \mu \mathrm{M})$ was used to rule out the involvement of the NADPH oxidase system in cellular production of ROS (c) and in the phagocytosis of IgG latex beads (d) induced by histamine. Apocynin-treated cells are represented in slashed columns both in (c and $\mathbf{d}$ ). Data are expressed as mean \pm SEM $(n=3-16)$ and as a percentage of control. ${ }^{*} P<0.05$, ${ }^{* *} P<0.01$, and ${ }^{* *} P<0.001$, using one-way ANOVA followed by Bonferroni's multiple comparison test

production induced by $100 \mu \mathrm{M}$ histamine was fully inhibited by H1R or H4R antagonists (Fig. 4b and Additional file 1: Figure S1) and mimicked by H1R $(P<0.01)$ or H4R $(P<0.05)$ agonists (Fig. 4b). The coadministration of both H1R and H4R antagonists with histamine blocked histamine-induced ROS production to the same level as both antagonists individually (data not shown). These data suggest that histamineinduced ROS production occurs via H1R and H4R activation, both in N9 cell line and primary murine microglia cell cultures. Then, apocynin was used to clarify the specific role of the Nox system in microglia ROS generation induced by histamine. Apocynin significantly inhibited histamine-induced ROS production in N9 microglial cells to levels similar to the controls $(P<0.001$, Fig. 4c). Interestingly, apocynin also fully abrogated histamine-induced IgG beads phagocytosis $(P<$ 0.05 , Fig. $4 \mathrm{~d}$ ). The concentration of apocynin used did not interfere with microglial cell death as evaluated by terminal deoxynucleotidyl transferase dUTP nick end labeling (TUNEL) and propidium iodide (PI) assays (data not shown). These results suggest that Nox activation and subsequent ROS production are involved in histamineinduced phagocytosis. Accordingly, histamine significantly increased Nox1 protein levels at 6 and $12 \mathrm{~h}$ posttreatment, both in the N9 cell line and primary murine microglial cells (Fig. 5a, b). Nox1 labeling was found preferentially at the luminal side of the plasma membrane, suggesting membrane recruitment of Nox1 signaling cascade (Fig. 5c). In contrast, no differences were observed regarding Nox 2 and Nox4 expression levels in histaminetreated cells as compared with the controls (Additional file 2: Figure S2). Functional activation of Nox1 is dependent on the activation of a small GTPase, Rac1. We found that histamine increased the expression levels of Rac1 $1 \mathrm{~h}$ after treatment, both in the N9 cell line and primary murine microglial cells (Fig. 5d, e). To prove the involvement of Nox1 signaling pathway on histamine-induced phagocytosis, we performed the same IgG bead phagocytosis protocol on primary cultures of microglial cells obtained from 


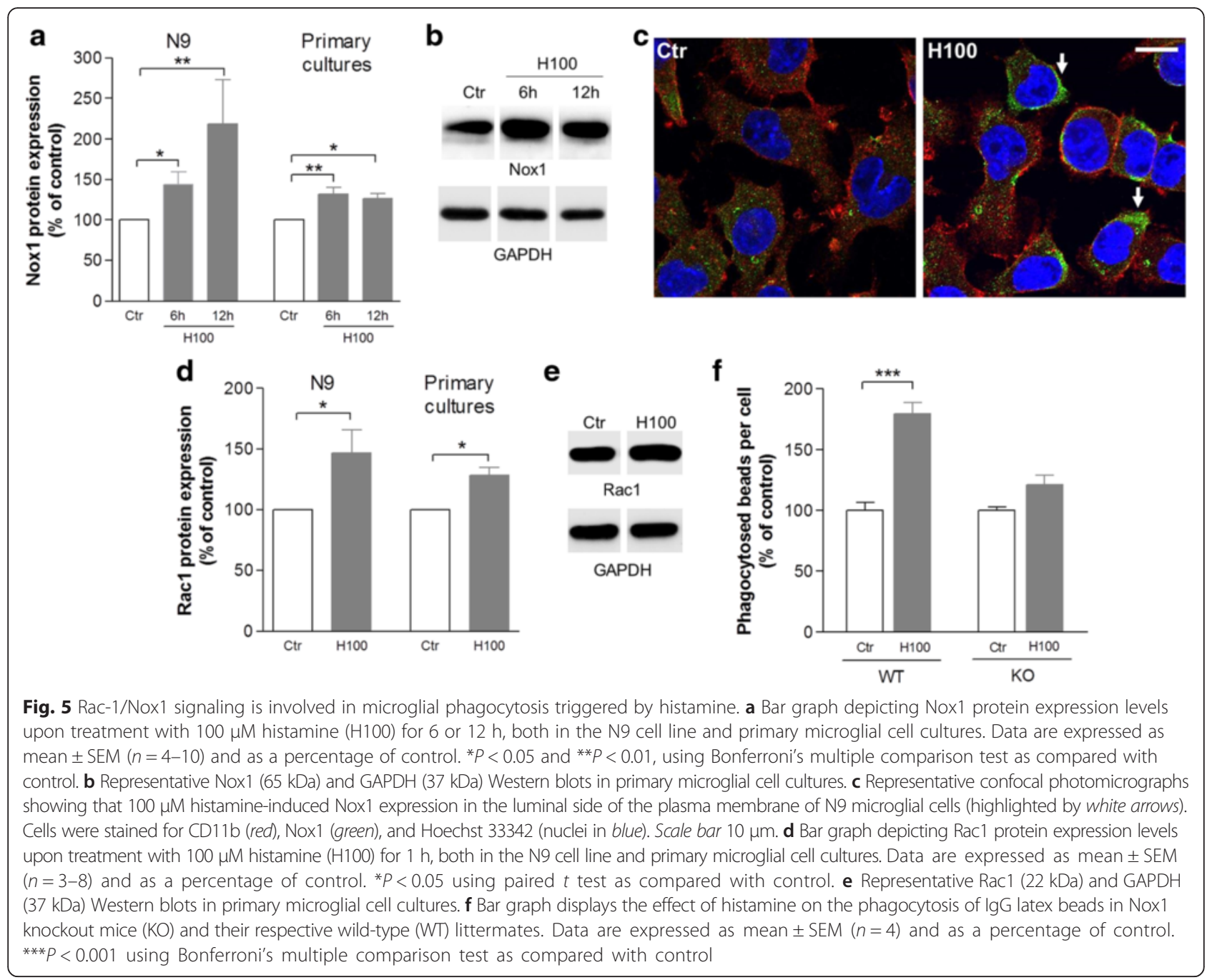

Nox1-KO mice and matched WT littermates. We found that Nox1 deficiency inhibits histamine-induced phagocytosis (Fig. 5f). Altogether, these results suggest that the Nox1/Rac1 signaling and the resultant ROS production are involved in histamine-induced microglial phagocytosis.

\section{Histamine-induced microglial activation modulates DA neuronal survival via $H 1 R$ activation}

We then explored the consequences of histamineinduced microglia activation in DA neuronal survival in vivo. We found that the stereotaxic injection of histamine in the SN of adult C57BL/6 mice for 7 days induced about 40-50 \% decrease of $\mathrm{TH}+$ cells as compared with saline-treated mice $(P<0.001$; Fig. 6a, b). To disclose the involvement of histamine receptors, we then co-injected histamine with the H1R or H4R antagonists in the SN. We found that only H1R antagonist was able to abolish the neurotoxic effect of histamine (Fig. 6a). Histamine-induced DA toxicity was also abolished by annexin V and apocynin (AnX V + H100: 108.9 \pm 3.0; Apo + H100: $84.9 \pm 10.9 ; n=5$, as compared with saline mice - set to $100 \%$; Fig. 6a). Annexin V or apocynin per se did not modify significantly the number of $\mathrm{TH}+$ cells as compared with saline animals (data not shown). In accordance with previous in vitro data (Fig. 5), Nox1 protein levels were increased in the $\mathrm{SN}$ of histamine-treated mice (Fig. 6c, d). H1R antagonist completely abolished histamine-induced Nox1 expression (Fig. 6c). Nox1 labeling was found predominantly in the perinuclear region of microglial cells (Fig. 6e). Altogether, our findings suggest that histamine, via H1R activation, induces microglial activation and ultimately the death of susceptible DA neurons, possibly by Nox1dependent oxidative signaling and PS-mediated microglial phagocytosis.

\section{Discussion}

Herein, we aimed to disclose the role of histamine and its receptors in microglia activation, namely in phagocytosis and ROS production, and ultimately to explore the 


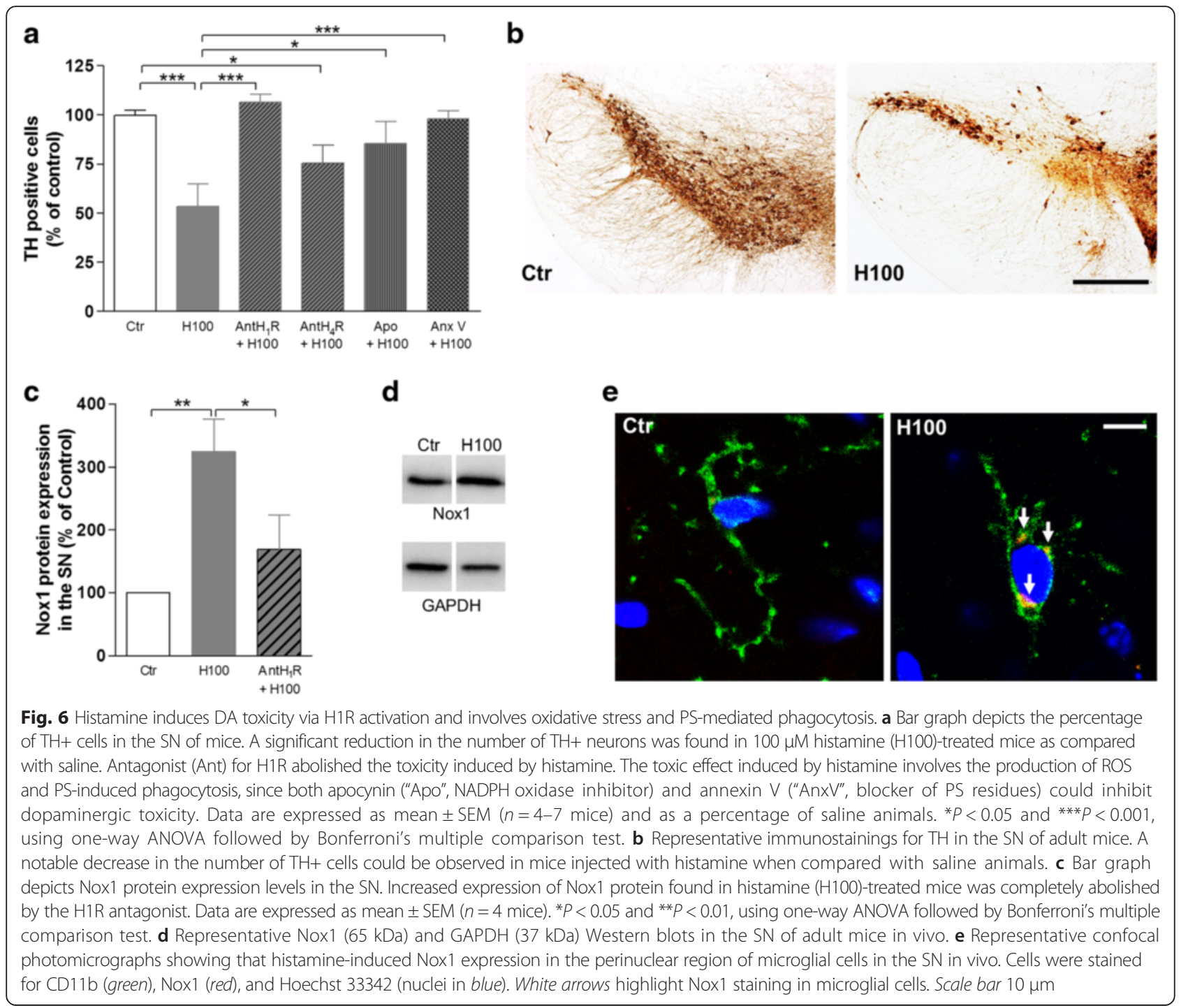

functional consequences of this inflammatory response in DA neuronal survival.

First, we found that histamine induces the phagocytosis of IgG-opsonized latex beads via H1R activation. This is in accordance with other reports showing that histamine can also induce phagocytosis in macrophages $[40,41]$. In contrast, other reports argue that histamine inhibits macrophage phagocytosis $[42,43]$. These contradictory studies may be due to the different types of cells used, range of histamine concentrations, and/or different experimental protocols. On the other hand, microglial cells have other surface receptors that recognize PS residues exposed on the surface of cells that underwent apoptosis or were subjected to certain stressing agents. The PS exposure acts as "eat-me" signals that can be recognized by microglial cells as targets to be eliminated $[44,45]$. We found that histamine could also potentiate phagocytosis/uptake of PS liposomes. Annexin V was able to inhibit histamine-induced PS phagocytosis, demonstrating that this process depends on the exposure of PS residues by liposomes. Interestingly, histamine induces both types of FcyR- and PSR-induced microglia phagocytosis, apparently triggering opposite inflammatory responses to the engulfment of distinct cargo. Classically, $\mathrm{F}_{\mathrm{c}} \gamma \mathrm{R}$ phagocytosis is associated to a M1 pro-inflammatory microglial phenotype, whereas M2 anti-inflammatory phenotype is mainly associated to PSR-phagocytosis. However, classic activation paradigms driving an M1 phenotype also lead to enhanced engulfment of apoptotic cells in vitro [46]. On the other hand, M2 phenotype driven by IL-4 and IL-13 increases the phagocytosis of myelin [47], whereas a M2 phenotype induced by glioma cancer stem cells reduces phagocytosis [48]. This suggests that histamine may be a versatile immune modulator by activating a particular phagocytosis pathway depending on a particular context. 
Activated microglia also release an inflammatory cocktail, including cytokines, phagocytic adaptor proteins (e.g., Milk Fat Globule-EGF Factor 8 Protein - MFG-E8), ROS, and NO, that may interfere with neuronal survival. Previously, we showed that histamine induces NO release by microglial cells [8]. Neither IL- $1 \beta$ nor tumor necrosis factor (TNF)- $\alpha$ was released upon histamine stimulation in the N9 microglial cell line that we used [7]. Herein, we show that histamine induces ROS production via $H 1 R$ and $H 4 R$ activation. A recent study showed that histamine induces TNF- $\alpha$, IL- 6 and ROS production and loss of mitochondrial membrane potential in rat primary microglial cultures, primarily via $\mathrm{H} 1 \mathrm{R}$ and H4R activation [10]. Both H1R and H4R activate phospholipase C (PLC) $[49,50]$. PLC can activate either PLC-inositol triphosphate (IP3) leading to intracellular calcium increase or PLC-protein kinase C (PKC) which in turn initiates nuclear factor (NF)-kappaB activation and can induce increased gene transcription, including inducible nitric oxide synthase (iNOS) expression and NO release [51-53]. This redundant and superimposed signaling pathways induced by H1R and H4R may mediate the release/production of inflammatory mediators (including NO and ROS) differently involved in several steps of microglial activity. Herein, our results demonstrated that histamine may also induce Rac1/Nox1 signaling triggering increased ROS levels which are responsible for microglia phagocytosis. Previous reports described that in microglia [54] and in DA neurons [55], Nox1 transcriptional regulation is modulated by PKCdelta. As mentioned above, this is especially important taking into account that H1R may activate PLC which is known to be the upstream regulator of PKCdelta activity. Moreover, it was recently reported that in dorsal root ganglion neurons, histamine activates PKCdelta via H1R [53]. Based on these assumptions, we may speculate that the downstream histamine signaling pathway may involve the activation of PLC by H1R, followed by PKCdelta activation inducing increased Nox1 expression and activation culminating in increased ROS production. In a number of studies, the involvement of Nox2 in microglia-dependent DA neurotoxicity has been also observed [56, 57]. These findings raise the question on whether other Nox isoforms are involved in microglia inducing oxidative stress in the nigrostriatal DA pathway. In the present work, we observed that Nox1 has a critical role in microglia phagocytosis as shown by experiments using Nox1-KO microglia cultures. Nevertheless, it is also plausible that microglia Nox2 may have a participation, probably in an upstream step, that with time is abolished given place to Nox1inducing oxidative stress by microglia. In the present work, we are also showing that histamine increases PSmediated microglia phagocytosis. Oxidation of PS is crucial for its externalization, and it was previously reported that Nox-dependent ROS generation is responsible for the selective oxidation of PS in neutrophils [58]. In addition, Brown and Neher [44] have shown that peroxynitrite produced by microglia is responsible for the externalization of PS on target cells to potentiate its phagocytosis. Also in this line, a study has shown that in activated microglia the $\mathrm{O}^{2-}$ produced by Nox1 may increase the levels of peroxynitrite that may diffuse and affect neighboring target cells [19]. Altogether, this supports the outcome of our results showing that in microglia, histamine increase Nox1 expression which is responsible for increasing ROS production and PS oxidation in target cells potentiating its phagocytosis.

The downstream signaling pathways induced by both Fc $\gamma R$ and PSR receptor activation lead to the remodeling of the microglial cytoskeleton through actin polymerization which is involved in the formation of pseudopodia. The formation of pseudopods is coincident with local remodeling of the cortical actin cytoskeleton and the formation of phagocytic cups involved in target engulfment $[16,59]$. In fact, we observed that histamine induced a robust actin punctuate staining in membrane ruffles. In accordance, we previously showed that LPS promotes microglial phagocytosis by modulating actin cytoskeleton reshuffling and the formation of phagocytic cups [60]. We also observed that histamine induced an increase of acetylated $\alpha$-tubulin levels, localized preferentially along microglial processes. Acetylation of $\alpha$-tubulin is a post-translational modification that serves as a marker of microtubule stabilization which is essential for spreading and phagocytosis [61]. These cytoskeleton modification events involving both actin polymerization and tubulin stabilization require activation of Rho GTPases, namely Rac1 and cdc42 [62-64]. This is in agreement with the increased levels of Rac1 expression induced by histamine in our microglial cell line. Rac1 is involved in the activation of Nox, in particular the Nox1 isoform, but also in cytoskeleton alterations required for microglial phagocytosis.

We then hypothesize that histamine-induced microglial activation could be related to the modulation of DA survival in vivo. In accordance with previous studies [27, 65], histamine was able to induce DA neuronal death accompanied by microglial reactivity. The neurotoxic effect induced by histamine was prevented by blocking H1R. Recently, it was also shown that histamine impairs midbrain DA development in vivo via H1R activation [66]. However, so far, the cellular and molecular mechanisms behind histamine-induced DA toxicity in the adult brain in vivo are not known. We hypothesize that histamine may induce an inflammatory milieu that encompasses increased ROS levels that triggers DA neurons to expose PS on their outer membrane leaflet stimulating microglial phagocytosis, oxidative stress, and ultimately DA neuronal death. Indeed, 
we found that histamine induces DA neuronal death via H1R activation, an effect accompanied with increased Nox1 protein levels. Interestingly, in the present experimental in vivo paradigm, Nox1 was found in the perinuclear region of the microglial cells. Additionally, Nox1 expression was also found in neurons (Additional file 3: Figure S3), as we have previously showed that Nox1 is upregulated on neurons in response to other in vivo injury paradigms such as ischemia or paraquat and 6hydroxydopamine (6-OHDA)-mediated neuronal death $[34,67,68]$. Therefore, we cannot exclude the putative involvement of neuronal Nox1 activation in the modulation of DA cell survival in vivo. We also found that histamineinduced PS exposure in the membranes of DA neurons and annexin $\mathrm{V}$ was able to abolished histamine-induced DA cell death. We suggest that oxidative stress induced by histamine, such as the production of peroxynitrite formed by the reaction between $\mathrm{NO}$ and $\mathrm{O}^{2-}$, may trigger PS exposure on DA neurons which may become vulnerable to microglial phagocytosis $[14,45]$. This particular type of neuronal loss referred as phagoptosis was also observed in animal models of PD and could be prevented by using phagocytosis inhibitors [69]. In fact, the "eat-me" signaling induced by PS exposure was reversible, so that blocking of phagocytosis through binding of PS by annexin V was sufficient to rescue DA toxicity induced by histamine. Recent studies also showed that microglial cells appear to migrate towards intoxicated/damaged DA neurons and present clear phagocytic characteristics, such as engulfing gliaptic contacts, nucleation/clustering of the actin cytoskeleton, and an increase in Golgi apparatus protein machinery in the $\mathrm{SN}$ of both 1-methyl-4-phenyl-1,2,3,6-tetrahydropyridine (MPTP)treated mice and macaques [70, 71]. Gliaptic contacts include the contact of microglial cell processes and cell bodies with DA neurites and cell bodies. Importantly, the inhibition of Rho-associated kinase (ROCK) activity prevents microglial migration and the formation of gliapses to protect damaged DA neurons from elimination. Altogether, both phagoptosis and the formation of gliaptic contacts may be involved in the unnecessary phagocytic elimination of DA neurons. Thus, blocking microglial migration and phagocytic activity might preserve degenerating neurons and induce neuroprotection. However, we cannot exclude that higher histamine concentrations may induce direct DA neuronal death without involving "primary phagocytosis" by microglia. In fact, we have previously shown that the secretome of histamine-treated microglia cells trigger DA cell death in vitro [8], and the direct application of histamine to a N27 rat DA cell line was able to induce a slight reduction of cell viability (about $25 \%$ reduction, data not show). This may suggest that histamine induces DA cell loss by both soluble and contact factors, and the contribution of each component may depend on the complexity of the experimental model used (in vivo versus in vitro) and the interaction with other brain cells. Therefore, molecules that prevent neuroinflammation and microglia activation, in particular microglial phagocytosis, may offer prospective clinical therapeutic benefit for neurodegenerative disease associated with an inflammatory profile, such as PD. Yet, future studies are needed to further disclose the role of histamine and antihistamines in PD, by using toxin-induced (e.g., MPTP or 6-OHDA) models combined with H1R conditional KO models to discriminate the temporal and differential contribution of H1R in both dopaminergic neurons and microglia. In accordance with our data, others also showed a neuroprotective and/or anti-inflammatory effect of antihistamines (e.g., H1R or H3R antagonists) in vivo in models of amyotrophic lateral sclerosis [72], temporal lobe epilepsy [73], and ischemia [74]. In this context, histamine receptors, especially microglia H1R, may be an interesting target to induce neuroprotection in neuroinflammatory-related diseases.

\section{Conclusions}

In the healthy brain, histamine is present at nanomolar concentrations in the CSF of humans and rodents [75]. Importantly, circulating levels of histamine and histaminergic innervations are robustly increased following brain injury or degeneration. Under these pathological conditions, the inflammatory response may trigger degranulation of mast cells, leading to a massive release of histamine in the CSF and in the brain parenchyma [22, 23, 76]. These evidences support the pathophysiological relevance of the histamine concentrations used in this study. Therefore, unraveling the cellular and molecular mechanisms triggered by histamine in neurodegenerative conditions, and particularly in PD, is of outmost relevance. In particular, the role of histamine on microglial activity has been recently uncovered and we were the first to show that N9 microglial cells express all histamine receptors and that histamine modulates microglial motility and cytokine release [7]. Herein, we show that histamine is an important modulator of microglial phagocytosis and ROS production, both components involved in the vulnerability and cell death of DA neurons in the $\mathrm{SN}$ in vivo. To the best of our knowledge, we were the first to show that the Nox signaling is involved in histamineinduced neuroinflammation and neurodegeneration. Importantly, histamine $\mathrm{H} 1$ antihistamines may be used as efficient therapeutic targets to prevent histamine-induced microglia activation and subsequent DA neuronal death in the context of PD and, eventually, other neurodegenerative diseases which are accompanied by microglia inflammation.

\section{Additional files}

Additional file 1: Figure S1. Histamine-induced ROS production via H1R and H4R activation in primary microglial cell cultures. Cellular ROS production induced by $100 \mu \mathrm{M}$ histamine (H100) was blocked by an H1R antagonist 
(AntH1R, mepyramine maleate, $1 \mu \mathrm{M}$ ) or H4R antagonist (AntH4R, JNJ7777120, $5 \mu \mathrm{M})$. Data are expressed as mean $\pm \operatorname{SEM}(n=5)$ and as percentage of control. ${ }^{* *} P<0.01$ and ${ }^{* * *} P<0.001$, using one-way ANOVA followed by Dunnett's test. (TIF 251 KB)

Additional file 2: Figure S2. Nox2 and Nox4 expression. Bar graphs depict Nox2 (A) and Nox4 (B) protein expression levels upon treatment of microglial cells with $100 \mu \mathrm{M}$ histamine for several time points. LPS $(100 \mathrm{ng} / \mathrm{ml})$ was used as a positive control. Data are expressed as mean \pm SEM $(n=2-8)$ and as a percentage of control. ${ }^{*} P<0.05$, one-way ANOVA, Bonferroni's multiple comparison test. (TIF $161 \mathrm{~KB}$ )

Additional file 3: Figure S3. Histamine-induced Nox1 immunostaining in dopaminergic neurons in the $\mathrm{SN}$ in vivo. Representative confocal photomicrographs showing that histamine-induced Nox 1 expression in the dopaminergic cells in the SN in vivo. Cells were stained for TH (green), Nox1 (red), and Hoechst 33342 (nuclei in blue). Scale bar $10 \mu \mathrm{m}$. (TIF $98 \mathrm{~KB}$ )

\section{Abbreviations}

$\mathrm{DA}$, dopaminergic neurons; HR, histamine receptor; IL, interleukin; NADPH, nicotinamide adenine dinucleotide phosphate; NO, nitric oxide; Nox, NADPH oxidase; PD, Parkinson's disease; PS, phosphatidylserine; ROS, reactive oxygen species; SN, substantia nigra.

\section{Acknowledgements}

Not applicable.

\section{Funding}

This work was supported by FCT Portugal, FEDER and COMPETE, PTDC/SAUNEU/104415/2008, and L'Oréal-UNESCO Portugal for Women in Science. This work was also supported by FEDER funds through the POCI COMPETE 2020 - Operational Programme Competitiveness and Internationalization in Axis I - Strengthening research, technological development and innovation (Project No. 007491) and National Funds by FCT (Project UID/Multi /00709). The funders had no role in the study design, the data collection and analysis, the decision to publish, or the preparation of the manuscript.

\section{Availability of data and materials}

The authors do not wish to share their data.

\section{Authors' contributions}

SMR carried out the in vitro experiments and participated in the data analysis and the manuscript writing. TS carried out the in vivo experiments and participated in the data analysis and the interpretation. ACC carried out the Nox1 knockout primary microglia cultures and participated in the data analysis and the manuscript writing. RF participated in the in vivo phagocytosis assays. TS participated in the analysis of dopaminergic neuronal survival in vivo. GJ carried out the Nox1 knockout primary microglia cultures. ME participated in the in vitro and in vivo phagocytosis experiments. CS carried out the in vivo experiments. LC and JV participated in the in vivo phagocytosis assays. GA participated in the analysis of dopaminergic neuronal survival in vivo. AK participated in the in vitro and in vivo phagocytosis analysis. YSK carried out the Nox1 knockout primary microglia cultures and participated in the data analysis and the interpretation. LB conceived of the study, participated in the data analysis and the interpretation in its design and coordination, and drafted the manuscript. All authors read and approved the final manuscript.

\section{Competing interests}

The authors declare that they have no competing interests.

\section{Consent for publication}

Not applicable.

\section{Ethics approval and consent to participate}

Not applicable.

\section{Author details}

'Health Sciences Research Centre, Faculty of Health Sciences, University of Beira Interior, Covilhã, Portugal. ${ }^{2}$ Burnett School of Biomedical Sciences, College of Medicine, University of Central Florida, Orlando, FL, USA. ${ }^{3}$ Center for Neuroscience and Cell Biology, Coimbra, Portugal. ${ }^{4}$ Division of Cardiovascular Medicine and Department of Biomedical Engineering, University of Virginia, Charlottesville, VA, USA. ${ }^{5}$ Health Sciences Research Centre, University of Beira Interior, Av. Infante D. Henrique, 6200-506 Covilhã, Portugal.

Received: 7 February 2016 Accepted: 26 May 2016

Published online: 04 June 2016

\section{References}

1. Brown RE, Stevens DR, Haas HL. The physiology of brain histamine. Prog Neurobiol. 2001;63:637-72.

2. Katoh Y, Niimi M, Yamamoto Y, Kawamura T, Morimoto-Ishizuka T, Sawada M, Takemori H, Yamatodani A. Histamine production by cultured microglial cells of the mouse. Neurosci Lett. 2001;305:181-4.

3. Chikahisa S, Kodama T, Soya A, Sagawa Y, Ishimaru Y, Sei H, Nishino S Histamine from brain resident MAST cells promotes wakefulness and modulates behavioral states. PLoS One. 2013:8:e78434.

4. Passani MB, Blandina P. Histamine receptors in the CNS as targets for therapeutic intervention. Trends Pharmacol Sci. 2011:32:242-9.

5. Watanabe T, Taguchi Y, Shiosaka S, Tanaka J, Kubota H, Terano Y, Tohyama $\mathrm{M}$, Wada H. Distribution of the histaminergic neuron system in the central nervous system of rats; a fluorescent immunohistochemical analysis with histidine decarboxylase as a marker. Brain Res. 1984;295:13-25.

6. Panula P, Yang HY, Costa E. Histamine-containing neurons in the rat hypothalamus. Proc Natl Acad Sci U S A. 1984:81:2572-6.

7. Ferreira R, Santos T, Goncalves J, Baltazar G, Ferreira L, Agasse F, Bernardino L. Histamine modulates microglia function. J Neuroinflammation. 2012;9:90.

8. Rocha SM, Pires J, Esteves M, Graca B, Bernardino L. Histamine: a new immunomodulatory player in the neuron-glia crosstalk. Front Cell Neurosci. 2014:8:120.

9. Dong $H$, Zhang $W$, Zeng $X$, Hu G, Zhang $H$, He S, Zhang S. Histamine induces upregulated expression of histamine receptors and increases release of inflammatory mediators from microglia. Mol Neurobiol. 2014;49: $1487-500$

10. Zhu J, Qu C, Lu X, Zhang S. Activation of microglia by histamine and substance P. Cell Physiol Biochem. 2014;34:768-80.

11. Alvarez XA, Franco A, Fernandez-Novoa L, Cacabelos R. Effects of neurotoxic lesions in histaminergic neurons on brain tumor necrosis factor levels. Agents Actions. 1994;41 Spec No:C70-72.

12. Fernandez-Novoa L, Franco-Maside A, Alvarez XA, Cacabelos R. Effects of histamine and alpha-fluoromethylhistidine on brain tumor necrosis factor levels in rats. Inflamm Res. 1995:44:55-7.

13. Alvarez XA, Franco A, Fernandez-Novoa L, Cacabelos R. Blood levels of histamine, IL-1 beta, and TNF-alpha in patients with mild to moderate Alzheimer disease. Mol Chem Neuropathol. 1996;29:237-52.

14. Neher JJ, Neniskyte U, Brown GC. Primary phagocytosis of neurons by inflamed microglia: potential roles in neurodegeneration. Front Pharmacol. 2012;3:27

15. Noda M, Suzumura A. Sweepers in the CNS: microglial migration and phagocytosis in the Alzheimer disease pathogenesis. Int J Alzheimers Dis. 2012;2012:891087

16. Sierra A, Abiega O, Shahraz A, Neumann H. Janus-faced microglia: beneficial and detrimental consequences of microglial phagocytosis. Front Cell Neurosci. 2013;7:6.

17. Peterson L, Flood PM. Oxidative stress and microglial cells in Parkinson's disease. Mediators Inflamm. 2012;2012:401264

18. Mossakowski AA, Pohlan J, Bremer D, Lindquist R, Millward JM, Bock M, Pollok K, Mothes R, Viohl L, Radbruch M, et al. Tracking CNS and systemic sources of oxidative stress during the course of chronic neuroinflammation. Acta Neuropathol. 2015;130:799-814.

19. Cheret C, Gervais A, Lelli A, Colin C, Amar L, Ravassard P, Mallet J, Cumano A, Krause $\mathrm{KH}$, Mallat M. Neurotoxic activation of microglia is promoted by a nox 1-dependent NADPH oxidase. J Neurosci. 2008:28:12039-51.

20. Fernandez-Novoa L, Cacabelos R. Histamine function in brain disorders. Behav Brain Res. 2001:124:213-33.

21. Cacabelos R, Torrellas C, Fernandez-Novoa L, Aliev G. Neuroimmune crosstalk in CNS disorders: the histamine connection. Curr Pharm Des. 2016:22:819-48. 
22. Anichtchik OV, Rinne JO, Kalimo H, Panula P. An altered histaminergic innervation of the substantia nigra in Parkinson's disease. Exp Neurol. 2000;163:20-30

23. Panula P, Nuutinen S. The histaminergic network in the brain: basic organization and role in disease. Nat Rev Neurosci. 2013;14:472-87.

24. Shan L, Bao AM, Swaab DF. The human histaminergic system in neuropsychiatric disorders. Trends Neurosci. 2015;38:167-77.

25. Rinne JO, Anichtchik OV, Eriksson KS, Kaslin J, Tuomisto L, Kalimo H, Roytta M, Panula P. Increased brain histamine levels in Parkinson's disease but not in multiple system atrophy. J Neurochem. 2002;81:954-60.

26. Binukumar BK, Bal A, Gill KD. Chronic dichlorvos exposure: microglial activation, proinflammatory cytokines and damage to nigrostriatal dopaminergic system. Neuromolecular Med. 2011;13:251-65.

27. Vizuete ML, Merino M, Venero JL, Santiago M, Cano J, Machado A. Histamine infusion induces a selective dopaminergic neuronal death along with an inflammatory reaction in rat substantia nigra. J Neurochem. 2000;75:540-52.

28. Ferreira R, Xapelli S, Santos T, Silva AP, Cristovao A, Cortes L, Malva JO. Neuropeptide $Y$ modulation of interleukin-1\{beta\} (IL-1\{beta\})-induced nitric oxide production in microglia. J Biol Chem. 2010;285:41921-34.

29. Cristovao AC, Saavedra A, Fonseca CP, Campos F, Duarte EP, Baltazar G. Microglia of rat ventral midbrain recovers its resting state over time in vitro: let microglia rest before work. J Neurosci Res. 2010;88:552-62.

30. Hosmane S, Tegenge MA, Rajbhandari L, Uapinyoying P, Kumar NG, Thakor $\mathrm{N}$, Venkatesan A. Toll/interleukin-1 receptor domain-containing adapter inducing interferon-beta mediates microglial phagocytosis of degenerating axons. J Neurosci. 2012;32:7745-57.

31. Schafer DP, Lehrman EK, Kautzman AG, Koyama R, Mardinly AR, Yamasak R, Ransohoff RM, Greenberg ME, Barres BA, Stevens B. Microglia sculpt postnatal neural circuits in an activity and complement-dependent manner. Neuron. 2012;74:691-705

32. Nielsen $H H$, Ladeby $R$, Fenger $C$, Toft-Hansen $H$, Babcock AA, Owens $T$, Finsen B. Enhanced microglial clearance of myelin debris in T cell-infiltrated central nervous system. J Neuropathol Exp Neurol. 2009;68:845-56.

33. Lu Z, Elliott MR, Chen Y, Walsh JT, Klibanov AL, Ravichandran KS, Kipnis J. Phagocytic activity of neuronal progenitors regulates adult neurogenesis. Nat Cell Biol. 2011;13:1076-83.

34. Cristovao AC, Choi DH, Baltazar G, Beal MF, Kim YS. The role of NADPH oxidase 1-derived reactive oxygen species in paraquat-mediated dopaminergic cell death. Antioxid Redox Signal. 2009;11:2105-18.

35. G. Paxinos, Franklin KBJ: The mouse brain in stereotaxic coordinates. San Diego: Academic Press, second ed.; 2001.

36. Zhang QG, Laird MD, Han D, Nguyen K, Scott E, Dong Y, Dhandapani KM, Brann DW. Critical role

of NADPH oxidase in neuronal oxidative damage and microglia activation following traumatic brain injury. PLoS One. 2012;7:e34504.

37. Esteves MRC, Cristovao AC, Saraiva T, Rocha SCM, Baltazar G, Ferreira L, Bernardino L: Retinoic acid-loaded polymeric nanoparticles induce neuroprotection in a mouse model for Parkinson's disease. Front Aging Neurosci. 2015;7(20):1-10.

38. Bernardino L, Agasse F, Silva B, Ferreira R, Grade S, Malva JO. Tumor necrosis factor-alpha modulates survival, proliferation, and neuronal differentiation in neonatal subventricular zone cell cultures. Stem Cells. 2008;26:2361-71.

39. Bernardino L, Eiriz MF, Santos T, Xapelli S, Grade S, Rosa Al, Cortes L, Ferreira R, Braganca J, Agasse F, et al. Histamine stimulates neurogenesis in the rodent subventricular zone. Stem Cells. 2012;30:773-84.

40. Sternberg EM, Wedner HJ, Leung MK, Parker CW. Effect of serotonin (5-HT) and other monoamines on murine macrophages: modulation of interferongamma induced phagocytosis. J Immunol. 1987;138:4360-5.

41. Cochrane DE, Carraway RE, Miller LA, Feldberg RS, Bernheim H. Histamine releasing peptide (HRP) has proinflammatory effects and is present at sites of inflammation. Biochem Pharmacol. 2003;66:331-42.

42. Azuma Y, Shinohara M, Wang PL, Hidaka A, Ohura K. Histamine inhibits chemotaxis, phagocytosis, superoxide anion production, and the production of TNFalpha and IL-12 by macrophages via H2-receptors. Int Immunopharmacol. 2001;1:1867-75.

43. Radermecker M, Bury T, Saint-Remy P. Effect of histamine on chemotaxis and phagocytosis of human alveolar macrophages and blood monocytes. Int Arch Allergy Appl Immunol. 1989;88:197-9.

44. Brown GC, Neher JJ. Inflammatory neurodegeneration and mechanisms of microglial killing of neurons. Mol Neurobiol. 2010;41:242-7.
45. Fricker M, Neher JJ, Zhao JW, Thery C, Tolkovsky AM, Brown GC. MFG-E8 mediates primary phagocytosis of viable neurons during neuroinflammation J Neurosci. 2012;32:2657-66.

46. Chan A, Magnus T, Gold R. Phagocytosis of apoptotic inflammatory cells by microglia and modulation by different cytokines: mechanism for removal of apoptotic cells in the inflamed nervous system. Glia. 2001;33:87-95.

47. Durafourt BA, Moore CS, Zammit DA, Johnson TA, Zaguia F, Guiot MC, BarOr A, Antel JP. Comparison of polarization properties of human adult microglia and blood-derived macrophages. Glia. 2012;60:717-27.

48. Wu A, Wei J, Kong LY, Wang Y, Priebe W, Qiao W, Sawaya R, Heimberger AB. Glioma cancer stem cells induce immunosuppressive macrophages/ microglia. Neuro Oncol. 2010;12:1113-25.

49. de Esch IJ, Thurmond RL, Jongejan A, Leurs $\mathrm{R}$. The histamine $\mathrm{H} 4$ receptor as a new therapeutic target for inflammation. Trends Pharmacol Sci. 2005;26:462-9.

50. Kajihara Y, Murakami M, Imagawa T, Otsuguro K, Ito S, Ohta T. Histamine potentiates acid-induced responses mediating transient receptor potential V1 in mouse primary sensory neurons. Neuroscience. 2010;166:292-304.

51. Kuo CT, Chiang LL, Lee CN, Yu MC, Bai KJ, Lee HM, Lee WS, Sheu JR, Lin CH. Induction of nitric oxide synthase in RAW 264.7 macrophages by lipoteichoic acid from Staphylococcus aureus: involvement of protein kinase C- and nuclear factor-kB-dependent mechanisms. J Biomed Sci. 2003;10:136-45.

52. Galeotti N, Malmberg-Aiello P, Bartolini A, Schunack W, Ghelardini C. H1-receptor stimulation induces hyperalgesia through activation of the phospholipase C-PKC pathway. Neuropharmacology. 2004;47:295-303.

53. Valtcheva MV, Davidson S, Zhao C, Leitges M, Gereau RW. Protein kinase Cdelta mediates histamine-evoked itch and responses in pruriceptors. Mol Pain. 2015:11:1.

54. Miller RL, Sun GY, Sun AY. Cytotoxicity of paraquat in microglial cells: Involvement of PKCdelta- and ERK1/2-dependent NADPH oxidase. Brain Res. 2007;1167:129-39.

55. Cristovao AC, Barata J, Je G, Kim YS. PKCdelta mediates paraquat-induced Nox1 expression in dopaminergic neurons. Biochem Biophys Res Commun. 2013;437:380-5.

56. Kim YS, Choi DH, Block ML, Lorenzl S, Yang L, Kim YJ, Sugama S, Cho BP, Hwang O, Browne SE, et al. A pivotal role of matrix metalloproteinase-3 activity in dopaminergic neuronal degeneration via microglial activation. Faseb J. 2007:21:179-87.

57. Purisai MG, McCormack AL, Cumine S, Li J, Isla MZ, Di Monte DA. Microglial activation as a priming event leading to paraquat-induced dopaminergic cell degeneration. Neurobiol Dis. 2007;25:392-400.

58. Arroyo A, Modriansky M, Serinkan FB, Bello RI, Matsura T, Jiang J, Tyurin VA, Tyurina YY, Fadeel B, Kagan VE. NADPH oxidase-dependent oxidation and externalization of phosphatidylserine during apoptosis in Me2SOdifferentiated HL-60 cells. Role in phagocytic clearance. J Biol Chem. 2002; 277:49965-75.

59. Lee WL, Mason D, Schreiber AD, Grinstein S. Quantitative analysis of membrane remodeling at the phagocytic cup. Mol Biol Cell. 2007;18:2883-92.

60. Ferreira R, Santos $T$, Viegas M, Cortes L, Bernardino L, Vieira OV, Malva JO. Neuropeptide $Y$ inhibits interleukin-1beta-induced phagocytosis by microglial cells. J Neuroinflammation. 2011;8:169.

61. Binker MG, Zhao DY, Pang SJ, Harrison RE. Cytoplasmic linker protein-170 enhances spreading and phagocytosis in activated macrophages by stabilizing microtubules. J Immunol. 2007;179:3780-91.

62. Bijman MN, van Nieuw Amerongen GP, Laurens N, van Hinsbergh WW, Boven E. Microtubule-targeting agents inhibit angiogenesis at subtoxic concentrations, a process associated with inhibition of Rac1 and Cdc42 activity and changes in the endothelial cytoskeleton. Mol Cancer Ther. 2006;5:2348-57.

63. Ninkovic J, Roy S. Morphine decreases bacterial phagocytosis by inhibiting actin polymerization through CAMP-, Rac-1-, and p38 MAPK-dependent mechanisms. Am J Pathol. 2012;180:1068-79.

64. Konakahara S, Suzuki Y, Kawakami T, Saitou M, Kajikawa M, Masuho Y, Kohroki J. A neuronal transmembrane protein LRFN4 complexes with 14-3$3 \mathrm{~s}$ and NCK1 to induce morphological change in monocytic cells via Rac1mediated actin cytoskeleton reorganization. FEBS Lett. 2012;586:2251-9.

65. Arai H, Furuya T, Yasuda T, Miura M, Mizuno Y, Mochizuki H. Neurotoxic effects of lipopolysaccharide on nigral dopaminergic neurons are mediated by microglial activation, interleukin-1 beta, and expression of caspase-11 in mice. J Biol Chem. 2004;279:51647-53.

66. Escobedo-Avila I, Vargas-Romero F, Molina-Hernandez A, Lopez-Gonzalez R, Cortes D, De Carlos JA, Velasco I. Histamine impairs midbrain dopaminergic 
development in vivo by activating histamine type 1 receptors. Mol Brain. 2014;7:58.

67. Choi DH, Kim JH, Lee KH, Kim HY, Kim YS, Choi WS, Lee J. Role of neuronal NADPH oxidase 1 in the peri-infarct regions after stroke. PLoS One. 2015;10: e0116814.

68. Choi DH, Cristovao AC, Guhathakurta S, Lee J, Joh TH, Beal MF, Kim YS. NADPH oxidase 1-mediated oxidative stress leads to dopamine neuron death in Parkinson's disease. Antioxid Redox Signal. 2012;16:1033-45.

69. Emmrich JV, Hornik TC, Neher JJ, Brown GC. Rotenone induces neuronal death by microglial phagocytosis of neurons. FEBS J. 2013;280:5030-8.

70. Barcia C, Ros CM, Annese V, Carrillo-de Sauvage MA, Ros-Bernal F, Gomez A, Yuste JE, Campuzano CM, de Pablos V, Fernandez-Villalba E, Herrero MT. ROCKVCdc42-mediated microglial motility and gliapse formation lead to phagocytosis of degenerating dopaminergic neurons in vivo. Sci Rep. 2012; 2:809.

71. Barcia C, Ros CM, Ros-Bernal F, Gomez A, Annese V, Carrillo-de Sauvage MA, Yuste JE, Campuzano CM, de Pablos V, Fernandez-Villalba E, Herrero MT. Persistent phagocytic characteristics of microglia in the substantia nigra of long-term Parkinsonian macaques. J Neuroimmunol. 2013;261:60-6.

72. Apolloni S, Fabbrizio P, Parisi C, Amadio S, Volonte C. Clemastine confers neuroprotection and induces an anti-inflammatory phenotype in SOD1(G93A) mouse model of amyotrophic lateral sclerosis. Mol Neurobiol. 2016;53:518-31.

73. Bhowmik M, Saini N, Vohora D. Histamine H3 receptor antagonism by ABT239 attenuates kainic acid induced excitotoxicity in mice. Brain Res. 2014; 1581:129-40.

74. Yan H, Zhang X, Hu W, Ma J, Hou W, Zhang X, Wang X, Gao J, Shen Y, Lv J, et al. Histamine $\mathrm{H} 3$ receptors aggravate cerebral ischaemic injury by histamine-independent mechanisms. Nat Commun. 2014;5:3334.

75. Croyal M, Dauvilliers Y, Labeeuw O, Capet M, Schwartz JC, Robert P. Histamine and tele-methylhistamine quantification in cerebrospinal fluid from narcoleptic subjects by liquid chromatography tandem mass spectrometry with precolumn derivatization. Anal Biochem. 2011;409:28-36.

76. Cacabelos R, Yamatodani A, Niigawa H, Hariguchi S, Tada K, Nishimura T, Wada $H$, Brandeis L, Pearson J. Brain histamine in Alzheimer's disease. Methods Find Exp Clin Pharmacol. 1989;11:353-60.

\section{Submit your next manuscript to BioMed Central and we will help you at every step:}

- We accept pre-submission inquiries

- Our selector tool helps you to find the most relevant journal

- We provide round the clock customer support

- Convenient online submission

- Thorough peer review

- Inclusion in PubMed and all major indexing services

- Maximum visibility for your research

Submit your manuscript at www biomedcentral.com/submit

) Biomed Central 